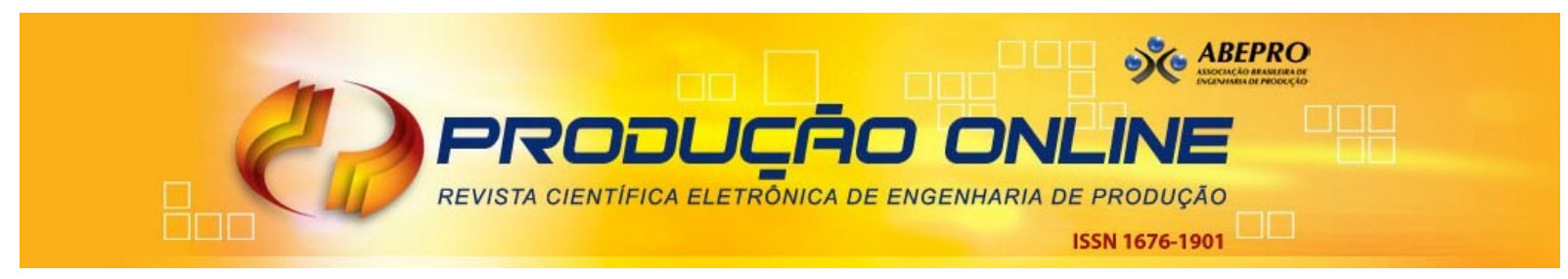

\title{
A PRODUTIVIDADE EM SERVIÇOS: UMA ANÁLISE À LUZ DA REVISÃO SISTEMÁTICA DE LITERATURA
}

\section{PRODUCTIVITY IN SERVICES: A SYSTEMATIC REVIEW}

\author{
Noel Torres Júnior* E-mail: noelface@gmail.com \\ Ana Lúcia Miranda Lopes*E-mail analopes.ufmg@gmail.com \\ * Universidade Federal de Minas Gerais (UFMG), Belo Horizonte, MG
}

Resumo: Por meio do método Revisão Sistemática da Literatura (RSL), este trabalho realizou uma análise do tema produtividade em serviços. Para tanto, quatorze periódicos da área de Gestão de Operações e a base de dados Scielo foram consultados. Os trabalhos foram analisados com relação a seis critérios de classificação: i) tipo de estudo; ii) setor pesquisado; iii) filiação dos autores; iv) abordagem metodológica predominante; v) temas abordados; e vi) métodos utilizados nas análises comparativas de desempenho. Com relação a esses critérios, verificou-se que a maior parte dos trabalhos utiliza a modelagem para avaliar a produtividade, principalmente por meio da metodologia de programação linear - Data Envelopment Analysis (DEA). Observou-se que a grande maioria dos autores tem origem acadêmica, havendo poucas publicações de pesquisadores oriundos de empresas ou trabalhos que apresentam ambos os tipos de pesquisadores. Este trabalho identificou quatro temas recorrentes nas pesquisas, ou seja, alguns artigos focalizaram no estabelecimento de indicadores de produtividade e na sua análise ao longo do tempo, comparando o desempenho de diferentes empresas ou setores. Outros identificaram especificidades e dificuldades da mensuração da produtividade em serviços em relação às empresas de manufatura. Diferentes trabalhos propuseram indicadores para mensuração da produtividade em serviços. Finalmente, à luz dos principais livros-textos de gestão de operações de serviços e da literatura consultada, este trabalho identificou as principais estratégias e métodos para a melhoria da produtividade de serviços. Constatou-se que produtividade em serviços é um tema promissor de pesquisa.

Palavras-chave: Produtividade em Serviços. Produtividade. Revisão Sistemática da Literatura. Desempenho. Data Envelopment Analysis.

Abstract: Through the method of Systematic Review of Literature (SRL), this study conducted an analysis of productivity in services. For this purpose, fourteen journals of Operations Management and Scielo database were consulted. The studies were analyzed with respect to six criteria for classification: i) type of study, ii) investigated business sector, iii) affiliation of authors, iv) prevailing methodological approach, v) themes, e vi) methods used in comparative analyzes of performance. It was found that the greatest amount of work used the modeling approach to assess the productivity, particularly by linear programming methodology - Data Analysis Envelopment (DEA). It was observed that the vast majority of authors are academic, there are few publications of researchers from companies or that have both types of researchers. The study identified four recurring themes in the articles. Then, some studies have focused on the establishment of productivity indicators and their analysis over time, comparing the performance of different firms or industries. Other studies have identified the characteristics and difficulties of measuring productivity in services in relation to manufacturing companies. Different studies have proposed indicators to measure productivity in services. Finally, in light of the main textbooks on operation's management and service literature, this study identified key strategies and methods for improving productivity in services. It was found that the theme productivity in services is a promising research topic. 
Keywords: Productivity in Services. Productivity. Systematic Review of Literature. Performance. Data Envelopment Analysis.

\section{INTRODUÇÃO}

A busca por maior produtividade se faz bem presente na literatura sobre gestão. Em decorrência disso, inúmeras métricas foram criadas e são utilizadas para avaliar a produtividade das organizações industriais (FOURASTIE, 1990; MOREIRA, 1991; SINK; TUTLE, 1993). A despeito da importância e do grande uso desse critério de desempenho no setor industrial, vários trabalhos apontam que a produtividade é baixa em várias organizações de serviços, uma vez que esses normalmente são entregues utilizando-se de uma grande quantidade de recursos e a um custo desnecessariamente alto (HENRICl, 1981; DRUCKER, 1991; ROACH, 1991). A despeito da sua relevância, a produtividade, como um conceito, tem sido muito negligenciada na pesquisa de serviços (FILIATRAULT; HARVEY; CHEBAT, 1996; OJASALO, 1999; GRÖNROOS, 2009), e o tema produtividade em serviços vem sendo sistematicamente apontado como um assunto importante para a agenda de pesquisa na área de operações (CHASE, 1996; JOHNSTON, 1999; NIE; KELLOGG, 1999; ROTH; MENOR, 2003; MACHUCA; GONZALEZ-ZAMORA; AGUILAR-ESCOBAR, 2007).

Diante desses fatos, este trabalho apresenta uma análise da literatura sobre a produtividade em serviços. Isso foi feito mediante a utilização do método Revisão Sistemática da Literatura (KITCHENHAM, 2004; TRANFIELD; DENYER; SMART, 2003). Quatorze periódicos da área de Gestão de Operações e a base de dados Scielo foram analisados. Os trabalhos foram avaliados levando-se em conta seis critérios de classificação: i) tipo de estudo; ii) setor pesquisado; iii) filiação dos autores; iv) abordagem metodológica predominante; v) temas abordados; e vi) métodos utilizados nas análises comparativas de desempenho da produtividade. À luz desses critérios, uma análise dos trabalhos é apresentada. Essa análise indicou algumas características predominantes nas pesquisas sobre o tema.

Além disso, baseando-se nos trabalhos consultados e nos principais autores da área de operações de serviços, o texto identificou quatro temas recorrentes nas pesquisas. Nessa direção, o texto aponta as principais especificidades existentes na mensuração da produtividade em serviços, se comparadas aos bens industriais. 
Também descreve as diferentes abordagens e visões acerca dos métodos utilizados para mensuração da produtividade. Finalmente, à luz dos principais livros-textos de gestão de operações de serviços e da literatura consultada, aponta as principais práticas que os gestores podem adotar para a melhoria desse critério em serviços. Finalmente, a última seção encerra o presente artigo tecendo comentários sobre os principais resultados encontrados.

\section{A PRODUTIVIDADE EM SERVIÇOS}

De uma maneira genérica, a produtividade de um sistema produtivo qualquer pode ser definida como a relação entre o que é gerado pelo sistema (seus produtos ou outputs) e o que entra nesse sistema (seus insumos ou inputs), em um certo período de tempo. Ela implica o estabelecimento de duas categorias básicas de medidas: i) produtividade estática, originária da divisão das medidas dos outputs pelas medidas dos inputs, em um dado período de tempo; ii) produtividade dinâmica, definida como a relação entre medidas da produtividade estática em períodos diferentes, refletindo a variação da produtividade de um período para outro. Dependendo do número de inputs considerados, podem-se obter as seguintes categorias de produtividade:

$\checkmark$ produtividade parcial - quando se considera apenas um dos inputs usados (mão de obra, capital, energia, matérias-primas etc.);

$\checkmark$ produtividade total dos fatores - quando são considerados simultaneamente os inputs capital e mão de obra, que são ponderados de acordo com certas regras para dar uma medida única dos inputs;

$\checkmark$ produtividade total - quando se consideram todos os inputs. Entretanto, na prática, existem vários motivos pelos quais se torna muito difícil utilizar todos os inputs. Há que se considerar que alguns deles podem não estar disponíveis para o cálculo, e outros são virtualmente impossíveis de serem medidos, por mais inegáveis que sejam as suas contribuições (MOREIRA, 1991; SINK; TUTLE, 1993).

Segundo Moreira (1991), a produtividade apresenta diversos usos potenciais aos seus gestores. São eles: 
$\checkmark$ como ferramenta gerencial, juntamente com outros indicadores gerenciais, auxiliando no controle e monitoramento das ações implementadas pela empresa;

$\checkmark$ como instrumento de motivação, pois a existência de indicadores de produtividade pode servir de estímulo à adoção de melhorias;

$\checkmark$ auxiliando na previsão de necessidades futuras de recursos produtivos;

$\checkmark$ como indicador do crescimento relativo de áreas ou categorias funcionais dentro da empresa;

$\checkmark$ para comparação do desempenho de unidades de uma mesma empresa;

$\checkmark$ para comparação do desempenho de uma organização com o setor a que pertence;

$\checkmark$ como instrumento de análise das fontes de crescimento econômico - em nível de nação ou setores, verificando seu papel como indicador da evolução do agregado econômico, de sua ligação com riqueza e bemestar social.

Como a produtividade trata da razão entre o output e o input de um dado processo, faz-se necessário compreender o que quer dizer input e output no contexto de serviços. Os inputs variam conforme a natureza do negócio e podem incluir mão de obra (física e intelectual), materiais, energia e capital (terreno, edificações, equipamentos, sistemas de informação e ativos financeiros). O output também varia conforme a natureza do serviço. Em um serviço que processa primordialmente pessoas, como é o caso de um hospital, por exemplo, existem diversos tipos de intervenções que podem ser realizadas e que são aplicadas a diferentes pessoas, as quais, por sua vez, reagem de modos distintos a cada uma delas. Dessa maneira, avaliar as inevitáveis diferenças entre resultados se torna complexo. Alguns pacientes melhoram, outros desenvolvem complicações e, infelizmente, alguns falecem. Já em empresas de serviços que processam primordialmente as posses de seus clientes, a tarefa da medição da produtividade pode ser mais simples. Muitas dessas organizações podem ser vistas como empresas quase manufatureiras, em virtude de executarem tarefas rotineiras com inputs e outputs de fácil medição. Depreende-se daí que um grande problema na medição da produtividade em serviços diz respeito à variabilidade que se faz intensamente presente na maioria deles (LOVELOCK; WIRTZ, 2006). 
A produtividade de uma operação está diretamente relacionada à eficácia com que os recursos em um processo - seja industrial, seja de serviço - são transformados em resultados econômicos para seu provedor e valor para seus clientes. Dentro dessa lógica, uma alta produtividade contribui para gerar lucro para o provedor de serviço, além de valor para seus clientes. Esse conceito, contudo, se apresenta de uma forma simplificada e incompleta, uma vez que pressupõe que a qualidade permanece inalterada com o aumento da produtividade. Nas organizações de serviços, a produtividade e a qualidade percebida devem ser compreendidas como fenômenos inseparáveis. Algumas vezes melhorar a satisfação do cliente e melhorar a produtividade concomitantemente podem ser objetivos incompatíveis, já que melhorar a produtividade pode ter um impacto negativo sobre a qualidade (ARMISTEAD; MACHIN, 1998; GRÖNROOS; OJASALO, 2004; JOHNSTON; JONES, 2004; OJASALO, 1999).

Portanto, para a avaliação do desempenho em serviços, um novo conceito de produtividade carece ser elaborado. Esse setor convive com o dilema da produtividade, que consiste na difícil tarefa de balancear receitas com os custos. É preciso resgatar que o conceito de produtividade tradicional foi desenvolvido para os fabricantes de bens físicos como um conceito de eficiência de manufatura. Desse modo, muitos modelos de produtividade e instrumentos de medição existentes foram derivados dentro do contexto de manufatura. Assim, eles partem da pressuposição de que produção e consumo são processos separados, em que os clientes não participam no processo de produção. Ainda que suas preferências sejam incorporadas nos Outputs, os sistemas de produção industrial são fechados. Os modelos de produtividade tradicionais e seus instrumentos de medida foram desenvolvidos para tais sistemas. Nos serviços, a simultaneidade entre processo e consumo, em que os clientes participam ativamente, faz com que os recursos possam ser padronizados até certo grau, tornando-se difícil de estimar a quantidade de inputs necessários para a realização de um dado output. Por conseguinte, as interações que são criadas pelo provedor de serviço e seus clientes podem influenciar a eficiência do processo de serviço (ARMISTEAD; MACHIN, 1998; GRÖNROOS; OJASALO, 2004; JOHNSTON; JONES, 2004; MCLAUGHLIN; COFFEY, 1990). 
Grönroos e Ojasalo (2004) consideram que a melhoria da produtividade é obtida por meio da compreensão do papel exercido pelo cliente no processo de entrega do serviço. Essa possibilita que o provedor apreenda o conhecimento necessário que deve ser adquirido pelo cliente para lidar com os vários aspectos do serviço, evitando que esse cliente cometa enganos e encontre dificuldades para recebê-lo. Com esse conhecimento, o provedor pode ainda informar adequadamente o seu público de modo que este se torne mais ciente do que esperar do serviço, criando uma percepção adequada e favorecendo a qualidade percebida.

Consequentemente, a produtividade do serviço depende do progresso da relação entre o cliente e o provedor, uma vez que a competência do cliente em participar do processo de serviço de modo mais amigável e rápido favorece a eficiência do provedor e pode também melhorar a qualidade percebida pelo cliente (GRÖNROOS; OJASALO, 2004).

Diante do que foi exposto, o Quadro 1 sintetiza as principais diferenças para medição da produtividade entre empresas de serviços e de manufatura.

Quadro 1 - Diferenças para medição da produtividade entre empresas de serviços e de manufatura

\begin{tabular}{|c|c|}
\hline $\begin{array}{l}\text { Premissas incluídas no conceito de } \\
\text { Produtividade voltado para a manufatura }\end{array}$ & $\begin{array}{l}\text { Características dos serviços que afetam } \\
\text { produtividade em contextos de serviço }\end{array}$ \\
\hline $\begin{array}{l}\text { - A produção e o consumo são separados } \\
\text { - A produtividade é medida em um sistema } \\
\text { fechado } \\
\text { - A qualidade percebida depende apenas do } \\
\text { resultado }\end{array}$ & $\begin{array}{l}\text { - A produção e o consumo são processos } \\
\text { parcialmente simultâneos, com interações que } \\
\text { influenciam a qualidade, isto é, um sistema aberto } \\
\text { - A qualidade percebida depende tanto do } \\
\text { resultado quanto do processo } \\
\text { - Dificuldades para separar os inputs da produção } \\
\text { de seus resultados }\end{array}$ \\
\hline $\begin{array}{l}\text { - Os clientes não participam do processo de } \\
\text { produção } \\
\text { - A qualidade percebida não é influenciada } \\
\text { pelo processo de produção }\end{array}$ & $\begin{array}{l}\text { - Os clientes participam do processo de produção } \\
\text { existindo: } \\
\text { - alguma incerteza dos inputs induzidos } \\
\text { pelos clientes no processo de serviço, } \\
\text { seus efeitos variam de uma situação para } \\
\text { outra; } \\
\text { os inputs induzidos pelos clientes afetam a } \\
\text { eficiência dos inputs levados pela empresa } \\
\text { no processo; } \\
\text { a qualidade percebida também é } \\
\text { influenciada pelo processo de produção do } \\
\text { serviço. }\end{array}$ \\
\hline
\end{tabular}

Fonte: Ojasalo (1999, p.59)

Cook, Goh e Chung (1999) reportam a existência de várias propostas de tipologias de serviço, e algumas delas serão tratadas neste trabalho. Nessa direção, as tipologias propostas por Chase (1978) e por Wemmerlöv (1990) merecem 
destaque. Elas destacam a influência da presença do cliente na eficiência da operação. Segundo esses autores, a interação direta do cliente com o processo cria certa perturbação na operação, portanto processos cujos clientes têm um contato indireto ou nenhum contato com o sistema de serviço podem ser projetados na lógica predominante de busca de eficiência e produtividade. Já Silvestro, Fitzgerald e Johnston (1992) propuseram uma tipologia de classificação considerando seis variáveis: foco nos equipamentos ou nas pessoas, tempo de contato com o cliente por transação, grau de customização, grau de discrição, orientação para o backoffice (retaguarda) ou front-office (linha de frente), e foco em produtos ou processos. À luz dessas características e baseando-se no volume de processamento de pessoas da operação, esses autores definiram três tipos básicos de operações de serviço:

$\checkmark$ Serviços profissionais: serviços com volume de transações relativamente baixo, alto grau de personalização, orientação para o processo, tempo de contato relativamente alto, mais valor agregado nas atividades de linha de frente e funcionários da linha de frente com alto grau de discrição.

$\checkmark$ Lojas de serviços: serviços que se enquadram nessa categoria costumam ter níveis intermediários no que diz respeito às características citadas. Têm um tempo de contato médio com clientes e nível médio de customização e discrição. O recurso principal pode estar voltado tanto para pessoas como para equipamentos, orientação de sua estrutura direcionada para o frontoffice ou back-office. Já o volume de processamento/dia por funcionário oscila entre os valores extremos que caracterizam os serviços de massa e os serviços profissionais.

$\checkmark$ Serviços de massa: serviços em que o volume de transações com clientes é alto, envolvendo limitado tempo de contato e pouca personalização. As ofertas são predominantemente orientadas para o produto, e o valor agregado é maior nas atividades de retaguarda. Os funcionários de linha de frente têm baixo grau de discrição.

Considerando a tipologia proposta pelos autores Silvestro, Fitzgerald e Johnston (1992), os serviços de massa, em função de seu maior volume de processamento e de suas características operacionais, conseguem obter menores custos e maior produtividade. 
Tendo em vista as diferentes considerações propostas pelos vários autores que abordam o critério de desempenho produtividade em serviços, alguns requisitos devem ser acatados na formulação de indicadores de produtividade. São eles:

$\checkmark$ o output deve ser visto como importante para o cliente e deve estar relacionado à criação de valor na perspectiva do cliente;

$\checkmark$ o output deve ser definido levando-se em consideração o nível de qualidade desejado para o serviço;

$\checkmark$ o cliente deve se tornar uma parte do conceito de produtividade;

$\checkmark$ o volume de processamento da operação e a interação direta do cliente com o processo produtivo afetam a produtividade;

$\checkmark$ as medidas de produtividade devem também estar relacionadas com 0 consumidor;

$\checkmark$ os indicadores de produtividade devem ser constantemente avaliados e revistos;

$\checkmark$ devem-se utilizar medidas que contemplem, em certo grau e a contento, a complexidade e a diversidade das operações de serviços (BLOIS, 1984; CHASE, 1978; GRÖNROOS; OJASALO, 2004; JOHNSTON; JONES, 2004; KLASSEN; RUSSELL; CHRISMAN, 1998; MOREIRA, 1991; OJASALO, 1999; SAHAY, 2005; SILVESTRO; FITZGERALD; JOHNSTON, 1992; VUORINEN; JARVINEN; LEHTINEN, 1998; WEMMERLÖV, 1990).

\section{MÉTODOS ADOTADOS NA PRESENTE PESQUISA}

Este trabalho pode ser caracterizado como teórico conceitual, mais especificamente direcionado à busca e à revisão da literatura sobre o tema produtividade em serviços na área de gestão de operações. Para tanto, apoiou-se no método de pesquisa Revisão Sistemática de Literatura (RSL).

Segundo Kitchenham (2004), a RSL pode ser entendida como uma forma de identificar, avaliar e interpretar as pesquisas disponíveis, referentes a uma questão de investigação, ou a uma área temática, ou a um fenômeno de interesse. Várias razões podem ser apontadas para a adoção desse método de pesquisa, as mais comuns são: 
$\checkmark$ identificar eventuais lacunas nas pesquisas atuais, a fim de sugerir novas áreas para investigação;

$\checkmark$ fornecer um quadro ou pano de fundo que possibilite posicionar adequadamente um tema ou área de pesquisa;

$\checkmark$ examinar a extensão em que evidências empíricas suportam ou mesmo contradizem hipóteses teóricas, ou mesmo para desenvolver uma nova hipótese;

$\checkmark$ fornecer melhor embasamento teórico à pesquisa.

Segundo Kitchenham (2004), a RSL apresenta algumas características que a diferenciam da revisão de literatura convencional, a saber:

$\checkmark$ é conduzida utilizando um protocolo de revisão que especifica a questão de pesquisa a ser abordada e os métodos que serão utilizados para executar tal revisão;

$\checkmark$ é baseada em uma estratégia de pesquisa definida, que visa detectar grande parte da literatura relevante sobre o objeto de interesse;

$\checkmark$ documenta a estratégia de busca utilizada possibilitando aos leitores o acesso ao conteúdo utilizado pela pesquisa, portanto os leitores podem verificar, de modo preciso, a qualidade e o rigor do trabalho;

$\checkmark$ exige a explicitação dos critérios de inclusão e exclusão que foram utilizados na busca das referências;

$\checkmark$ finalmente, especifica quais informações foram obtidas das referências.

Esse método vem sendo utilizado extensivamente pela área médica, no entanto esta utiliza tanto a RSL como o método Meta-Análise. Este último pode ser entendido como uma síntese estatística dos estudos, possibilitando uma estimação dos efeitos dos tratamentos analisados e o estabelecimento de inferências acerca de hipóteses instituídas (GRENHALGH, 1997; LOVATO et al., 2007). Apesar de diferenças e especificidades existentes na área de gestão em relação à área médica, Tranfield, Denyer e Smart (2005) reportam a importância da aplicação da RSL para o desenvolvimento da pesquisa na área de gestão. 


\section{2 Etapas da Pesquisa}

Três etapas foram realizadas para a efetivação da revisão sistemática de literatura acerca do tema produtividade em serviços dentro da área de gestão de operações.

A primeira etapa consistiu na identificação dos objetivos da revisão e na escolha dos critérios de busca, bem como na definição dos periódicos a serem analisados.

Definiu-se explorar o tema produtividade em serviços na área de gestão de operações. A pesquisa buscou melhor compreender como esse tema é tratado por essa área de uma maneira geral. Após algumas buscas experimentais, definiu-se que as palavras de busca seriam: "produtividade em serviços/ service productivity/ productivity in service", "efetividade em serviços/ effectiveness in service/ service effectiveness", "eficiência em serviços/ efficiency in service/ service efficiency". Essas foram solicitadas em todos os campos de busca.

Para a análise dos dados, foram considerados apenas artigos em periódicos, uma vez que esses somente foram publicados após uma seleção e avaliação mais criteriosa que a normalmente existente em trabalhos de congressos e simpósios. Foram desconsideradas as análises de resumos de livros, dissertações e teses pelo fato de a base de dados dos periódicos da CAPES ainda divulgar um número restrito de trabalhos desse tipo.

Tendo-se como referência inicial as pesquisas bibliométricas acerca da área de gestão de operações de serviços realizadas pelos autores Machuca, GonzalezZamora e Aguilar-Escobar (2007) e Martins (2009), e considerando a importância do periódico para área, os autores selecionaram treze periódicos internacionais. Eles também incluíram no estudo a base de dados Scielo e a Revista Produção Online, uma vez que essas poderiam representar as principais pesquisas nacionais sobre esse tema. A Tabela 1 apresenta os periódicos analisados e o respectivo período de busca em cada um deles. 
Tabela 1 - Relação dos periódicos consultados e o respectivo período de referência

\begin{tabular}{lc}
\hline \multicolumn{1}{c}{ Periódicos } & Ano de referência \\
\hline Decision Science (DS) & $1980-2010$ \\
Harvard Business Review (HBR) & $1981-2010$ \\
International Journal of Operations and Production Management (IJOPM) & $1980-2010$ \\
International Journal of Production and Performance Management (IJPPM) & $1980-2010$ \\
International Journal of Production Economics (IJPE) & $1995-2010$ \\
International Journal of Service Industry Management (IJSIM) & $1990-2010$ \\
Journal of Operations Management (JOM) & $1989-1990$ \\
Journal of Service Research (JSR) & $1999-2010$ \\
Management Science (MS) & $1991-2010$ \\
Operations Research (OR) & $1981-2010$ \\
Production and Operations Management (POM) & $2003-2010$ \\
Revista Produção Online & $2001-2011$ \\
Service Bussiness (SB) & $2006-2010$ \\
The Service Industries Journal (SIJ) & $1980-2010$ \\
\hline
\end{tabular}

Fonte: Pesquisa dos Autores

A seleção dos trabalhos foi desenvolvida em três fases. Na primeira fase, as palavras de busca selecionaram uma grande quantidade de periódicos (1288 trabalhos). Posteriormente, baseando-se nos resumos de cada um deles, os trabalhos que não tratavam do tema produtividade em serviços como ponto central foram descartados, ou seja, permaneceram apenas 101 trabalhos após a primeira triagem. Todos esses trabalhos foram impressos e analisados, apenas 45 deles permaneceram nesta segunda triagem, portanto 56 trabalhos foram excluídos. Os principais motivos para a não-inclusão dos 56 trabalhos foram: i) tratavam da avaliação geral de desempenho nos serviços; ii) tratavam da gestão da operação como um todo; iii) abordavam a eficiência ou a eficácia dos serviços, mas não tratavam da produtividade ou da eficiência relativa de unidades produtivas. Finalmente, após essa segunda triagem, apenas 7 periódicos permaneceram. A Tabela 2 mostra os periódicos que foram analisados e a quantidade de artigos em cada um deles.

A seguir, os principais resultados do trabalho são apresentados. Os resultados codificados e sumarizados são apresentados no Anexo II, e as Tabelas 10 e 11 do Anexo I apresentam o critério de codificação utilizado. 
Tabela 2 - Relação de periódicos após a segunda triagem e a quantidade de artigos encontrados

\begin{tabular}{lc}
\hline Periódico/Base de Dados & Quantidade \\
\hline Harvard Business Review (HBR) & 04 \\
International Journal of Operations and Production Management (IJOPM) & 04 \\
International Journal of Productivity and Performance Management & 07 \\
International Journal of Service Industry Management (IJSIM) & 08 \\
Journal of Service Research (JSR) & 03 \\
Scielo & 02 \\
Revista Produção Online & 05 \\
The Service Industries Journal (SIJ) & 12 \\
\hline
\end{tabular}

Fonte: Pesquisa dos Autores

\subsection{Resultados Encontrados}

Mesmo levando em consideração um horizonte de tempo maior do que vinte anos, verificou-se um baixo volume de trabalhos acerca do tema produtividade em serviços, apenas 45 trabalhos. Isso sinaliza que o tema ainda não está sendo explorado de modo intenso pela área de gestão de operações. O número de trabalhos pode ser visualizado no Gráfico 1, que mostra a quantidade de trabalhos por ano. Uma análise de gráfico também revela certa flutuação desses trabalhos ao longo do tempo.

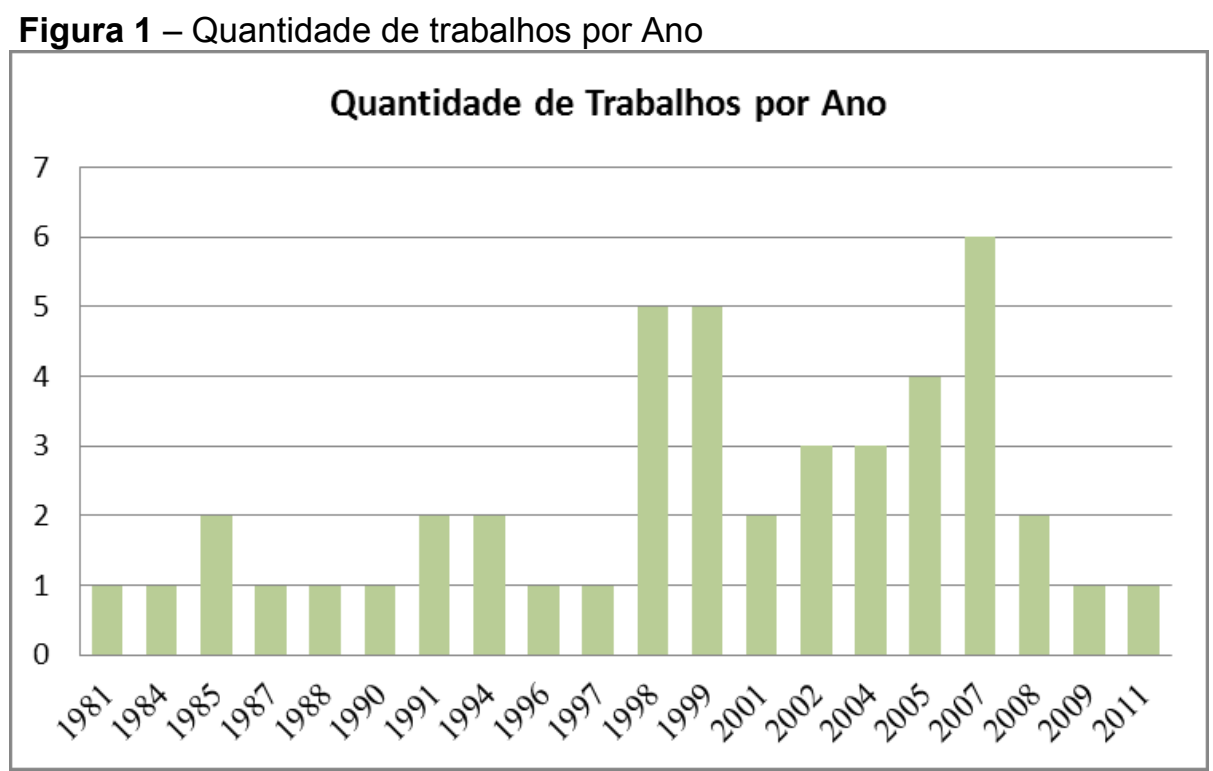

Fonte: Pesquisa dos Autores

A Tabela 3 mostra os principais tipos de pesquisa utilizados nos trabalhos pesquisados. A classificação do tipo de pesquisa foi baseada nos trabalhos de Machuca, Gonzalez-Zamora e Aguilar-Escobar (2007) e Nakano (2010). Verifica-se 
que uma maior quantidade de trabalhos utiliza a Modelagem, principalmente por meio da metodologia de programação linear - Data Envelopment Analysis (DEA). Em seguida, verifica-se um grande número de trabalhos utilizando a abordagem teórico conceitual. As abordagens Estudo em campo e Outros vêm logo em seguida.

Tabela 3 - Tipos de Estudo

\begin{tabular}{lcc}
\multicolumn{1}{c}{ Tipo de Estudo } & $\begin{array}{c}\text { Quantidade } \\
\text { de Trabalhos }\end{array}$ & Percentual \\
\hline Modelagem & 18 & 40 \\
Teórico Conceitual & 11 & 24 \\
Estudo em Campo: Estudo de Caso, Pesquisa-Ação, Etnografia & 7 & 16 \\
Outros: Experimento, Dados Históricos, Base de Dados & 6 & 13 \\
Survey & 3 & 7 \\
\hline
\end{tabular}

Fonte: Pesquisa dos Autores.

Uma análise da Tabela 4 revela que os trabalhos que utilizaram a abordagem teórico conceitual estão presentes em todos os períodos analisados. Isso pode ser interpretado como um indício de que esse tema ainda se encontra em fase de construção de conceitos, apontando um baixo nível de maturidade acadêmica sobre o mesmo (HANDFIELD; MELNYK, 1998).

Tabela 4 - Tipos de Estudo

\begin{tabular}{cccccc}
\hline Período & $\begin{array}{c}\text { Estudo em } \\
\text { Campo }\end{array}$ & Modelagem & Outros & Survey & $\begin{array}{c}\text { Teórico } \\
\text { Conceitual }\end{array}$ \\
\hline $1980-85$ & 0 & 0 & 0 & 0 & 4 \\
$1986-90$ & 0 & 0 & 1 & 0 & 2 \\
$1991-95$ & 0 & 0 & 3 & 0 & 1 \\
$1996-00$ & 3 & 4 & 0 & 2 & 3 \\
$2001-05$ & 2 & 8 & 1 & 0 & 1 \\
$2006-11$ & 2 & 6 & 1 & 1 & 0 \\
\hline
\end{tabular}

Fonte: Pesquisa dos Autores

A Tabela 5, a seguir, mostra os setores pesquisados nos trabalhos. Verificase uma grande diversidade de setores. 
Tabela 5 - Setores Analisados

Comércio e distribuição

Setor Pesquisado Quantidade

Correios e serviços de courier

Instituições financeiras e de seguros

Saúde

Serviços profissionais

Serviços públicos e empresas sem fins lucrativos

Telecomunicações

Transporte

Turismo, entretenimento, lazer e cultura

Serviços de Engenharia

Vários setores

Serviços de alto contato

Fonte: Pesquisa dos Autores

OBS.: Dos 45 trabalhos analisados, 09 trabalhos não fizeram referências a um setor específico.

Em relação à filiação dos pesquisadores, uma análise da Tabela 6 revela que a grande maioria é acadêmica, havendo poucas publicações de pesquisadores de empresas ou trabalhos que apresentam ambos os tipos de pesquisadores, o que pode significar que as empresas divulgam pouco seus estudos acerca do tema.

Tabela 6 - Filiação dos autores dos trabalhos analisados

\begin{tabular}{lcc}
\hline \multicolumn{1}{c}{ Filiações dos autores } & Quantidade & Percentual \\
\hline Instituições de Ensino e Pesquisa & 33 & 73 \\
Não mencionaram & 4 & 9 \\
Instituições de Ensino e Pesquisa /Empresas & 5 & 11 \\
Empresas & 3 & 7 \\
\hline
\end{tabular}

Fonte: Pesquisa dos Autores

A Tabela 7 apresenta a classificação dos trabalhos em relação às abordagens "quantitativa" e "qualitativa" por tipo de estudo. Verificou-se que a abordagem "quantitativa" tem sido mais realizada, uma vez que estudos desse tipo predominam nos tipos de pesquisa que foram mais utilizados nos trabalhos.

Tabela 7 - Abordagem metodológica predominante por tipo de estudo

\begin{tabular}{lcccc}
\multicolumn{1}{c}{ Tipo de Estudo } & $\begin{array}{c}\text { Quantitativa } \\
\text { e Qualitativa }\end{array}$ & Qualitativa & Quantitativa & Total \\
\hline Estudo em Campo: Estudo de Caso, & 0 & 5 & 2 & 7 \\
Pesquisa-Ação, Etnografia etc. & 0 & 0 & 17 & 17 \\
Modelagem /Simulação & 1 & 0 & 2 & 3 \\
Outros: Experimento, Dados Históricos, Base & 0 & 0 & 2 & 2 \\
de Dados & 0 & 0 & 0 & 0 \\
Survey & & &
\end{tabular}

Fonte: Pesquisa dos Autores 
A Tabela 8 , a seguir, mostra os principais métodos utilizados nas análises comparativas acerca da produtividade; destaca-se o uso da Data Envelopment Analysis (DEA) para esse fim.

Tabela 8 - Métodos utilizados nas análises comparativas

\begin{tabular}{lc}
\hline \multicolumn{1}{c}{ Método } & Quantidade de Trabalhos \\
\hline Data Envelopment Analysis $(D E A)$ & 12 \\
Data Envelopment Analysis $(D E A) /$ Análise de Regressão & 2 \\
Data Envelopment Analysis $(D E A) /$ Outros & 1 \\
Outros & 4 \\
\hline
\end{tabular}

Fonte: Pesquisa dos Autores

Uma análise detalhada dos trabalhos apontou quatro diferentes temas recorrentes na maioria deles:

$\checkmark$ alguns trabalhos focalizaram no estabelecimento de indicadores de produtividade e na sua análise ao longo tempo, comparando o desempenho de diferentes empresas ou setores. Esses trabalhos foram intitulados "Análises comparativas de desempenho em termos de produtividade";

$\checkmark$ outros trabalhos contextualizavam especificidades e dificuldades da mensuração da produtividade em serviços em relação às empresas de manufatura. Estes trabalhos foram intitulados "Contextualização da produtividade em serviços";

$\checkmark$ diferentes trabalhos procuraram identificar estratégias e métodos que poderiam ser utilizados pelas empresas de serviços para melhorarem a produtividade. Esses trabalhos foram intitulados "Estratégias e métodos para a melhoria da produtividade";

$\checkmark$ finalmente, alguns trabalhos propuseram indicadores para mensuração da produtividade em serviços e foram intitulados "Proposição de indicadores de produtividade".

Tendo como referência os quatro temas expostos anteriormente, a Tabela 9 apresenta os diversos temas abordados pelos trabalhos pesquisados. Alguns abordaram mais de um tema. Observou-se que a maioria dos artigos do tipo Teórico Conceitual se concentrava no tema "Contextualização da produtividade em serviços", e todos os trabalhos do tipo Modelagem/Simulação se concentravam no tema "Análises comparativas de desempenho em termos de produtividade". 
Tabela 9 - Principais temas abordados pelos trabalhos

\begin{tabular}{|c|c|c|}
\hline Temas Abordados & $\begin{array}{l}\text { Quantidade de } \\
\text { Trabalhos }\end{array}$ & Percentual \\
\hline $\begin{array}{l}\text { Análises comparativas de } \\
\text { produtividade }\end{array}$ & 16 & 36 \\
\hline $\begin{array}{l}\text { Análises comparativas de desempenho em termos de } \\
\text { produtividade / Contextualização da produtividade em serviços }\end{array}$ & 3 & 7 \\
\hline $\begin{array}{l}\text { Análises comparativas de desempenho em termos de } \\
\text { produtividade / Proposição de indicadores de produtividade }\end{array}$ & 2 & 4 \\
\hline Contextualização da produtividade em serviços & 10 & 22 \\
\hline $\begin{array}{l}\text { Contextualização da produtividade em serviços / Estratégias e } \\
\text { métodos para a melhoria da produtividade }\end{array}$ & 3 & 7 \\
\hline $\begin{array}{l}\text { Contextualização da produtividade em serviços / Proposição de } \\
\text { indicadores de produtividade }\end{array}$ & 7 & 16 \\
\hline Estratégias e métodos para a melhoria da produtividade & 3 & 7 \\
\hline Proposição de indicadores de produtividade & 1 & 2 \\
\hline
\end{tabular}

Fonte: Pesquisa dos Autores.

\section{TEMAS ACERCA DA PRODUTIVIDADE EM SERVIÇOS}

À luz dos trabalhos consultados e baseando-se em alguns dos principais livros-textos de gestão de operações de serviços, esta seção descreve os principais métodos utilizados para sua mensuração e as práticas sugeridas para a melhoria da produtividade nos serviços.

\subsection{A Mensuração da Produtividade}

Nesta subseção, são discutidas as abordagens existentes para se medir a produtividade de serviços. A despeito de existirem várias propostas, nenhuma solução final pode ser apresentada, uma vez que ainda não há suficientes pesquisas disponíveis sobre esse tema.

$\mathrm{Na}$ manufatura tradicional, a premissa de que a qualidade permanece constante apesar do aumento da produtividade torna relativamente fácil estimar a produtividade. Entretanto, em serviços, as medições de produtividade devem incluir uma avaliação do modo como determinado recurso poderá afetar a qualidade percebida do serviço e a própria capacidade de geração de receita para a organização. Além disso, essas medidas devem levar em conta o grau de variação da demanda e as consequências desse fato para a utilização da capacidade (GRÖNROOS, 2009). 
Considerando o exposto na subseção anterior, é possível inferir que existem várias dificuldades potenciais na identificação dos inputs e outputs que sejam apropriados para a mensuração da produtividade em serviços, uma vez que:

$\checkmark$ a produção, ou aquilo a ela equivalente, não possui uma unidade física de medida bem definida, ou não a possui de modo algum;

$\checkmark$ uma grande variedade de serviços pode ser oferecida por uma mesma organização;

$\checkmark$ é impossível dissociar quantidade de qualidade (VUORINEN; JARVINEN; LEHTINEN, 1998).

As dificuldades não atingem as várias organizações e suas atividades de serviço da mesma forma e intensidade. Há casos em que é relativamente simples escolher uma medida ou sistema de medidas, enquanto, em outras situações, é difícil. Do ponto de vista da teoria da medição, a representatividade dos itens escolhidos como medidas torna-se uma questão crucial. Portanto, a produtividade em serviços deve ser baseada em medidas que informem a quantidade e a qualidade dos outputs e inputs. Do ponto de vista prático, a organização deve responder adequadamente às seguintes perguntas:

$\checkmark$ Como a quantidade de entradas (inputs) e saídas (outputs) pode ser medida?

$\checkmark$ Como a qualidade das entradas (inputs) e saídas (outputs) pode ser avaliada? (GRÖNROOS, 2009; VUORINEN; JARVINEN; LEHTINEN, 1998)

Diante da dificuldade em escolher um único critério que abarque tantos aspectos e que informe a respeito da quantidade e da qualidade dos outputs e inputs, Johnston e Jones (2004) propõem que a mensuração da produtividade seja entendida por duas vertentes: (i) produtividade operacional e (ii) produtividade do cliente. A primeira é definida como uma função da taxa de saídas operacionais (recursos usados, clientes, receitas etc.) sobre as entradas (materiais, clientes, equipes, custos etc.), durante um dado período de tempo. A segunda é definida como uma função da taxa de saídas para o cliente (experiência, valores etc.) sobre as entradas demandadas (tempo, esforço, custos etc.). Para os autores, tanto uma quanto a outra devem ser utilizadas.

A Figura 2 ilustra dois tipos de componentes existentes na mensuração da produtividade de acordo com a visão dos autores Grönroos (2009) e Vuorinen, Jarvinen e Lehtinen (1998). 
Figura 2 - Dois componentes existentes para a mensuração da produtividade.

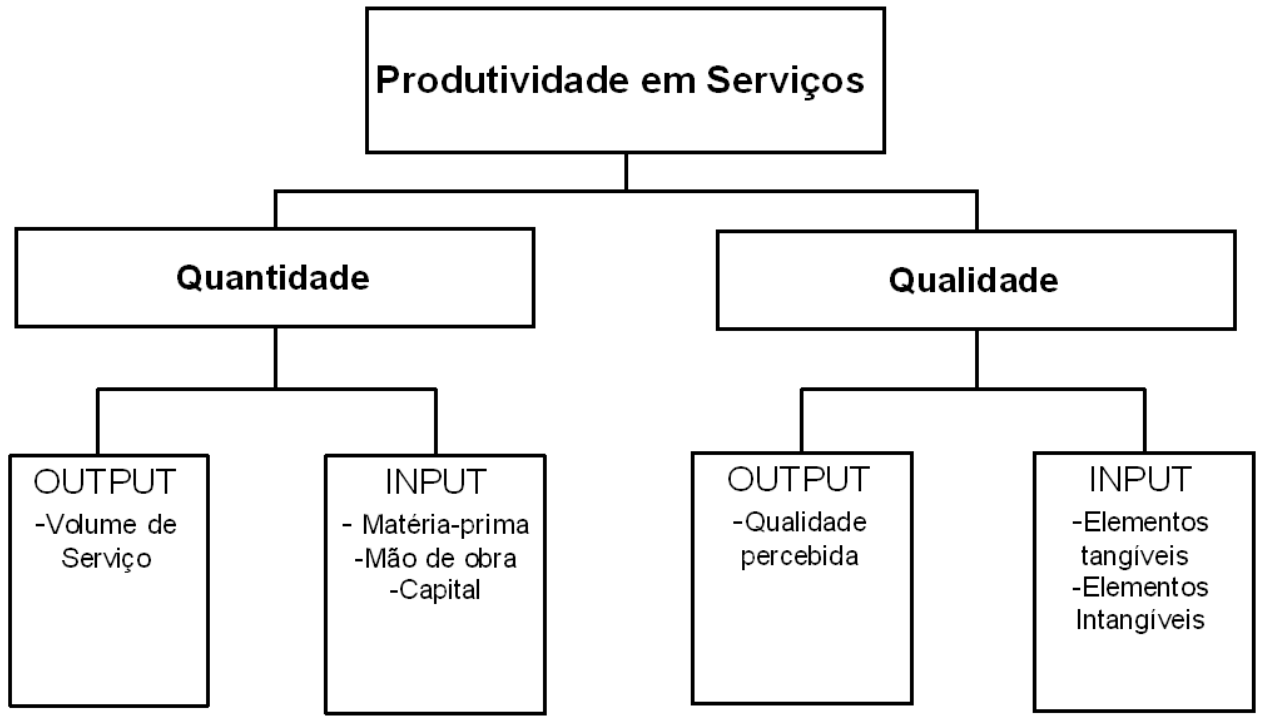

Fonte: Vuorinen; Jarvinen; Lehtinen (1998, p.383)

As medições físicas e financeiras são bastante utilizadas na avaliação da produtividade dos serviços. Usar apenas uma delas pode ser enganador, e utilizar medições combinadas também pode o ser. Os autores Osajalo (1999) e Grönroos (2009) retratam os prós e os contras das medições físicas, financeiras e combinadas da produtividade de serviços no Quadro 2. Essas medidas de produtividade parcial são utilizadas e podem fornecer informações importantes, entretanto, na visão desses autores, somente medições de produtividade global ou total dão a real informação sobre como um prestador de serviços está melhorando sua receita ou não.

Quadro 2 - Características das alternativas para medição da produtividade em serviços.

\begin{tabular}{|c|c|}
\hline Medições Físicas & $\begin{array}{l}\text { Aspectos de heterogeneidade e intangibilidade de serviços tornam as } \\
\text { medições físicas inadequadas. } \\
\text { Medições físicas ignoram variações na qualidade. } \\
\text { A produtividade total é difícil de medir, porque é problemático combinar } \\
\text { as quantidades de recursos de inputs utilizados. } \\
\text { É difícil obter informações precisas sobre quantidades. }\end{array}$ \\
\hline Medições Financeiras & $\begin{array}{l}\text { Medições financeiras sinalizam aspectos de heterogeneidade e } \\
\text { intangibilidade de serviços. } \\
\text { Não é necessário nenhum índice de preço, porque ambos, numerador e } \\
\text { denominador da medição de produtividade, são valores monetários } \\
\text { referentes ao mesmo período. }\end{array}$ \\
\hline $\begin{array}{l}\text { Combinações de } \\
\text { Medições Físicas e } \\
\text { Financeiras }\end{array}$ & $\begin{array}{l}\text { São experimentados os mesmos problemas que ocorrem nas medições } \\
\text { físicas. } \\
\text { Índices de preços são necessários, porque o numerador ou o } \\
\text { denominador são expressos em valores monetários. }\end{array}$ \\
\hline
\end{tabular}

Fonte: Grönroos (2009, p.224) 
Os autores McLaughlin e Coffey (1990) classificam as medidas de produtividade considerando o nível de agregação da razão ente output versus input, conforme ilustrado na Figura 3.

Figura 3 - Tipos de Indicadores de Produtividade

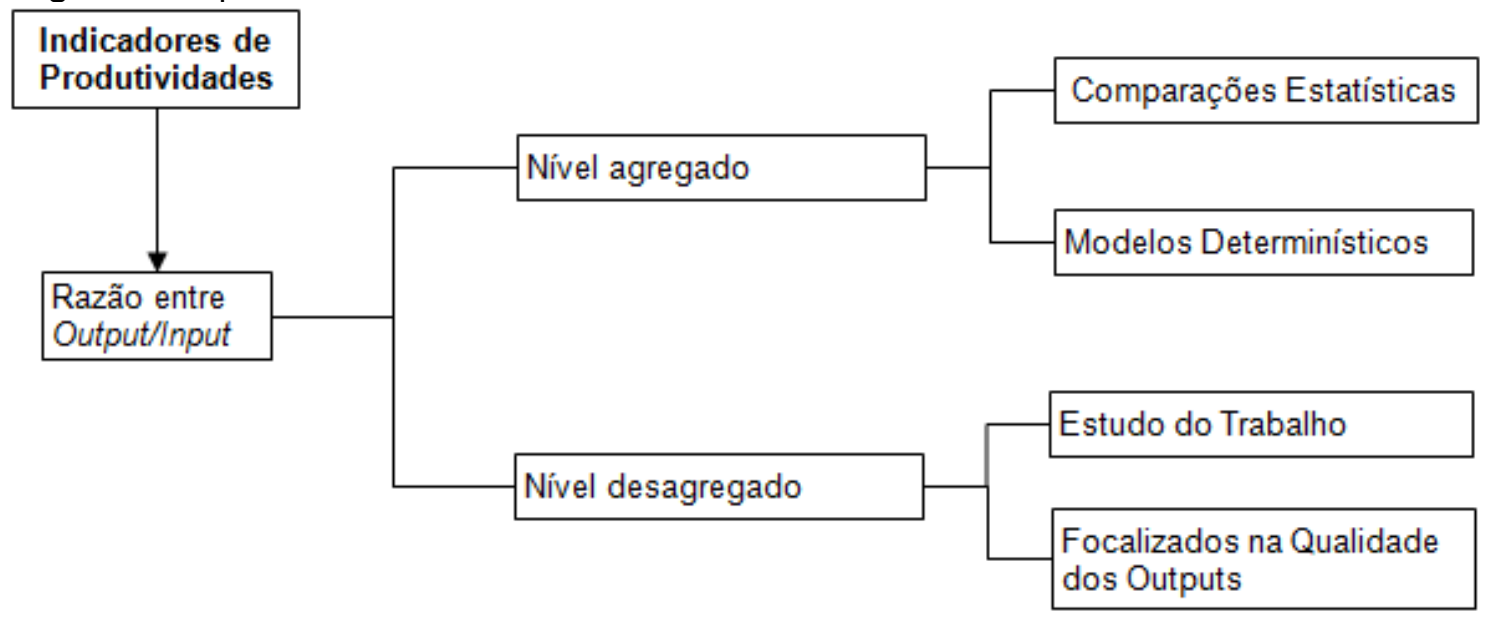

Fonte: Adaptado de Mclaughlin; Coffey (1990)

Considerando a classificação proposta pelos autores McLaughlin e Coffey (1990), este estudo identificou que vários trabalhos mensuram a eficiência técnica produtiva utilizando o modelo determinístico conhecido como Data Envelopment Analysis (DEA). A eficiência produtiva é medida por meio do modelo de programação linear que busca, em suas orientações, a redução de inputs ou expansão de outputs. (AL-SHAMMARI, 1999; ARAÚJO; CARMONA, 2002; BORENSTEIN; BECKER; PRADO, 2004; CHEN; CHEN; PENG, 2008; DE MELLO et al., 2005; DE ALMEIDA; MARIANO; REBELATTO, 2007; HILMOLA, 2007; JUNQUEIRA et al., 2007; KUMAR; GULATI, 2009; NACHUM, 1999a e 1999b; NAVARRO; CAMACHO, 2001; SIGALA; JONES; LOCKWOOD, 2005; SOUSA; RAMOS, 1999; WOODBURY; DOLLERY, 2004).

A metodologia $D E A$ é composta por um conjunto de modelos de programação linear utilizados para identificar a eficiência técnica produtiva de unidades tomadoras de decisão (Decision Making Units - DMU). Foi proposta por Charnes, Cooper e Rhodes, em 1978, para a avaliação de empresas públicas, mas rapidamente se expandiu e foi também aplicada na avaliação da eficiência de empresas privadas. Embora o modelo CCR, como foi chamado, tivesse sua aplicabilidade restrita às empresas operando sob retornos constantes de escala, em 1984, os autores Banker, Charnes e Cooper estenderam a metodologia para avaliação de empresas 
sob diferentes retornos de escala (constante, crescente e decrescente) criando, então, o modelo BCC. Sob a perspectiva desse método, a medida da produtividade de uma organização é similar à medição da eficiência de um sistema. Ela pode ser estabelecida como a razão das saídas pelas entradas. Torna-se possível comparar a eficiência de múltiplas unidades de serviço que fornecem serviços similares mediante a consideração explícita do uso de suas múltiplas entradas na produção de múltiplas saídas. Portanto, utilizando-se desse método, pode-se comparar um grupo de unidades de serviço, a fim de identificar as unidades relativamente ineficientes, medindo a magnitude das ineficiências e, pela comparação das unidades ineficientes com as eficientes, descobrir formas para reduzir as ineficiências (HAKSEVER et al., 2000).

\subsection{A melhoria da Produtividade}

A melhoria do desempenho é um grande objetivo perseguido pelo gestor de serviço. Um meio importante para o atendimento desse fim é o aumento da produtividade. Nessa direção, o presente texto aponta as diversas alternativas sugeridas para $\mathrm{o}$ atendimento desse propósito. Foram consultados alguns dos principais livros-textos de gestão de operações de serviços, além dos artigos encontrados na Revisão Sistemática da Literatura conduzida neste trabalho.

Para uma melhor compreensão do modo como as diversas alternativas podem ser implementadas, dividiu-se o serviço em seis elementos: i) Produto: refere-se aos benefícios e utilidades que são entregues ao cliente; ii) Processo: refere-se à rede de atividades paralelas e sequenciais que deve ser realizada para a entrega do serviço; iii) Recursos Técnicos e Físicos: refere-se aos recursos da empresa presentes no seu arranjo físico que são necessários para a concretização do serviço; iv) Sistemas de Controle: refere-se aos elementos de controle, como softwares, estrutura organizacional, normas e regulamentos, que apoiam a operação produtiva; v) Funcionários; e vi) Clientes do serviço (EDVARDSSON, 1997).

O Quadro 3, a seguir, sintetiza as alternativas encontradas para a melhoria da produtividade em serviços. 
Quadro 3 - Estratégias e métodos para a melhoria da produtividade em serviços

\begin{tabular}{|c|c|}
\hline Elementos do serviço & Estratégias e métodos para a melhoria da produtividade \\
\hline Produto & Padronizar os serviços \\
\hline Processo & $\begin{array}{l}\text { Aumentar o porte do negócio, de modo a ganhar mais eficiência, por } \\
\text { meio dos ganhos advindos com a economia de escala } \\
\text { Automatizar } \\
\text { Eliminar atividades que não agregam valor no processo } \\
\text { Melhorar o fluxo do processo, por meio do aumento da capacidade dos } \\
\text { recursos gargalos e/ou modificar a sequência das atividades do processo } \\
\text { Padronizar os processos }\end{array}$ \\
\hline $\begin{array}{c}\text { Recursos Técnicos e } \\
\text { Físicos }\end{array}$ & $\begin{array}{l}\text { Fazer com que sistemas e tecnologias deem mais suporte aos } \\
\text { funcionários e/ou à participação do cliente } \\
\text { Melhorar o arranjo físico } \\
\text { Reduzir o desperdício de materiais }\end{array}$ \\
\hline Sistema de Controle & $\begin{array}{l}\text { Desenvolver na organização uma cultura orientada para o serviço } \\
\text { Desenvolver valores internos que, por um lado, dão suporte ao bom } \\
\text { serviço e, por outro lado, fazem com que os funcionários se } \\
\text { conscientizem da necessidade de usar recursos inteligentemente } \\
\text { Programar um sistema cuidadoso de controle de custos em todas as } \\
\text { etapas do processo }\end{array}$ \\
\hline Funcionários & $\begin{array}{l}\text { Criar polivalência dos funcionários para a execução de diversas } \\
\text { atividades. } \\
\text { Direcionar as atividades menos complexas para a mão de obra menos } \\
\text { qualificada, de maneira a aumentar a disponibilidade da mão de obra } \\
\text { mais qualificada } \\
\text { Intensificar a especialização da mão de obra para a redução do seu } \\
\text { custo } \\
\text { Melhorar a capacidade técnica dos funcionários } \\
\text { Por limites ao arbítrio dos funcionários (estabelecimento de tarefas bem } \\
\text { definidas com baixo grau de discrição) ou dar maior autonomia aos } \\
\text { funcionários (maior liberdade de atuação no processo) }\end{array}$ \\
\hline Clientes do Serviço & $\begin{array}{l}\text { Aumentar a cooperação do cliente no processo de produção do serviço } \\
\text { ou limitar a participação do cliente } \\
\text { Influenciar o comportamento do cliente por meio de comunicações } \\
\text { publicitárias e redução de preços nos períodos de baixa procura ou } \\
\text { aumento nos preços nos períodos de pico, de forma a reduzir as filas ou } \\
\text { melhorar o grau de utilização dos recursos produtivos }\end{array}$ \\
\hline
\end{tabular}

Fonte: Adaptado de (ANUPINDI et al., 2006; BLUMBERG, 1994; DELAUNAY, 1999; FITZSIMMONS; FITZSIMMONS , 2005; GRÖNROOS, 2009; JOHNSTON; CLARK, 2008; LOVELOCK; WIRTZ, 2006; MARTIN JR.; HORNE; CHAN, 2001; OJASALO, 1999; SHAFTI; VAN DER MEER; WILLIAMS, 2007; SCHMENNER, 1999; TORRES JÚNIOR; MIYAKE, 2011; ZEITHAML; BITNER, 2011)

\section{CONCLUSÃO}

O trabalho apontou diversas especificidades para a definição e mensuração da produtividade entre empresas de serviços e de manufatura. $O$ texto também apontou algumas abordagens existentes para se medir a produtividade de serviços. Apesar das várias propostas apresentadas, nenhuma abordagem pode ser entendida como final. No entanto, observou-se uma quantidade significativa de trabalhos utilizando o Data Envelopment Analysis (DEA) para esse fim. 
Uma análise das diversas estratégias e métodos sugeridos para a melhoria da produtividade revela certa diversidade de opções, existindo algumas alternativas contraditórias entre si. Por exemplo, por um lado, alguns autores apregoam que a maior participação do cliente no processo prejudicaria o desempenho, pois tenderia a aumentar a variabilidade do processo de entrega do serviço. Essa visão é comumente chamada de abordagem da Linha de Produção em Serviços. Por outro lado, outros autores advogam a estratégia de aumentar a participação do cliente como um meio para melhorar o desempenho da empresa. Existem diferentes estratégias de automação, que dependem de quais tarefas serão automatizadas. Desse modo, as tarefas que eram executadas pelos funcionários podem ser automatizadas ou as decisões antes deixadas ao poder de discrição dos mesmos. A automatização das tarefas executadas pelos funcionários da linha de frente deve ser feita em tarefas que não prejudiquem a qualidade da interação desses com os clientes. Desse modo, os funcionários podem dedicar maior atenção aos clientes, melhorando a percepção da qualidade pelos mesmos. A automatização também pode ser utilizada para facilitar e melhorar as tarefas executadas pelos clientes. $O$ arranjo físico tem um grande papel na percepção da qualidade do serviço pelo cliente, e não se restringe apenas à melhoria do fluxo do serviço. Além disso, a melhoria das instalações físicas pode propiciar maior conforto e qualidade de vida para os funcionários, contribuindo indiretamente para a melhoria da produtividade.

Dos 45 artigos analisados neste trabalho, seis propuseram estratégias e métodos para a melhoria da produtividade. Todavia, apenas dois trabalhos focalizaram suas estratégias e métodos em serviços profissionais. Além de conter algumas das práticas sugeridas no Quadro 3, esses trabalhos enfatizaram a necessidade de as empresas melhorarem sua gestão como um todo para serem mais produtivas. Por conseguinte, os autores colocam a necessidade de se projetar um serviço focalizado e um processo de entrega compatível com o mesmo. Recomendam que o gerenciamento do serviço, como um todo, seja conduzido de forma mais profissionalizada.

A RSL apontou que o tema produtividade em serviços ainda é pouco estudado pelos pesquisadores da área de Gestão de Operações. No âmbito da pesquisa conduzida no Brasil, poucos trabalhos sobre esse tema foram encontrados, indicando que ele é ainda menos explorado pelos pesquisadores brasileiros se 
comparado à exploração por pesquisadores estrangeiros. Os trabalhos analisados mostram que a produtividade de serviços é muito mais complicada de se definir, mensurar e melhorar do que a produtividade de empresas de manufatura. Concomitantemente, esses aspectos apontam esse tema como promissor, devendo ser mais bem trabalhado pela comunidade acadêmica.

\section{Agradecimentos}

Este trabalho só foi possível graças ao apoio financeiro da FAPEMIG por meio do Programa Primeiros Projetos - Edital No 021/2008 - Processo No: APQ00332-09.

Os autores agradecem a valiosa contribuição dos alunos de Iniciação Científica Thais Lage Moreira e Mateus Henrique Toussaint Azevedo que participaram ativamente da pesquisa durante a condução da Revisão Sistemática da Literatura.

\section{REFERÊNCIAS}

AL-SHAMMARI, M. A multi-criteria data envelopment analysis model for measuring the productive efficiency of hospitals. International Journal of Operations and Production Management (IJOPM), v.19, n.09, p. 879-890, 1999.

ANUPINDI, R. et al. Managing business process flows: principles of operations management. $2^{\text {nd }} . e d$. New Jersey: Pearson Pretince Hall, 2006.

ARMISTEAD, C.; MACHIN, S. Business process management: implications for productivity in multi-stage service networks. International Journal of Service Industry Management (IJSIM), v.09, n.04, p. 323-336, 1998.

ARAÚJO, P. M. de Q.; CARMONA, C. U. De M. Eficiência de uma rede de agências bancárias utilizando: O modelo Data Envelopment Analysis - DEA. Revista Produção Online, v.2, n.2, 2002.

BIEMA, M. van; GREENWALD, B. Managing our way to higher service-sector productivity. Harvard Business Review (HBR), p.87-95, July-August 1997.

BLOIS, K. J. Productivity and Effectiveness in Service Firms. The Service Industries Journal (SIJ), v.4, n.3, p.49-60, 1984.

BLUMBERG, D. F. Strategies for improving field service operations productivity and quality.The Service Industries Journal (SIJ), v.14, n.2, p. 262-277, 1994. 
BORENSTEIN, D.; BECKER, J. L.; PRADO, V. J. do. Measuring the efficiency of Brazilian post office stores using data envelopment analysis. International Journal of Operations and Production Management (IJOPM), v.24, n.10, p. 1055-1078, 2004.

CHASE, R. B. Where does the customer fit in a service operation? Harvard Business Review, p. 137-42, Nov./Dec. 1978.

CHASE, R.B. The mall is my factory: reflections of a service junkie. Production and Operations Management, v.5, n.4, p.298-308, 1996.

CHEN, T.; CHEN, C.; PENG, S. Firm operation performance analysis using data envelopment analysis and balanced scorecard: a case study of a credit cooperative bank. International Journal of Productivity and Performance Management, v.57, n.07, p. 523-539, 2008.

COOK, D. P; GOH, C.; CHUNG, C. H. Service typologies: a state of the art survey. Production and Operations Management, v.8, n.3, p.318-338, 1999.

D'ALCANTARA, G. From service productivity to service regulation and regulating services. The Service Industries Journal (SIJ), v.7, n.2, p.143-152, 1987.

DE MELLO, J. C. C. B. S. et al. Eficiência DEA como medida de desempenho de unidades policiais. Revista Produção Online, v.5, n.3, 2005.

DE ALMEIDA, M. R.; MARIANO, E. B.; REBELATTO, D. A. do N. Análise de eficiência dos aeroportos internacionais brasileiros. Revista Produção Online, Edição Especial, 2007.

DELAUNAY, J. Capital and other inputs in the production of services: what impact on service relationships? International Journal of Service Industry Management (IJSIM), v.10, n.2, p. 157-170, 1999.

DRUCKER, P. The new productivity challenge. Harvard Business Review (HBR), p. 69-79, November-December 1991.

EDVARDSSON, B. Quality in new service development: key concepts and a frame of reference. International Journal of Production Economics, v. 52, p.31-46, 1997.

FILITRAUK, P.; HARVEY, J.; CHEBAT, J.C. Service quality and service productivity management practice. Industrial Marketing Management, v. 25, n. 3, p. 243-255, 1996.

FITZSIMMONS, J. A.; FITZSIMMONS, M. J. Administração de serviços: operações, estratégica e tecnologia da informação. 4. ed. Porto Alegre: Bookman, 2005.

FLETCHER, J.; SNEE, H. The Need for Output Measurements in the Service Industries: a Comment. The Service Industries Journal (SIJ), v.5, n.1, p. 73-78, 
1985.

FOURASTIÉ, J. A produtividade. São Paulo: Martins Fontes, 1990.

GEORGES, I. As relações com a produtividade: O caso do serviço de informações telefônicas. Tempo Social, v.14, n.1, p. 159-176, 2002.

GREENHALGH, T. How to read a paper: paper that summarise other papers (systematic reviews and meta-analyses). BMJ, v.315, p. 672-675, 1997.

GRÖNROOS, C. Marketing: gerenciamento e serviços. Rio de Janeiro: Elsevier, 2009.

GRÖNROOS, C.; OJASALO, K. Service productivity towards a conceptualization of the transformation of inputs into economic results in services. Journal of Business Research, v. 57, p. 414-423, 2004.

HAKSEVER, C. et al. Service management and operations. New Jersey: Prentice Hall, 2000.

HANDFIELD, R. B.; MELNYK, S. A. The scientific theory-building process: a primer using the case of TQM. Journal of Operations Management, v.16, p.321-339, 1998.

HAYWOOD-FARMER, J.; NOLLET, J. Productivity in professional services. The Service Industries Journal (SIJ), v.5, n.2, p.169-180, 1985.

HENRICI, S. B. How deadly is the productivity disease? Harvard Business Review (HBR), p.123-129, November/December, 1981.

HILMOLA, O. European railway freight transportation and adaptation to demand decline: efficiency and partial productivity analysis from period of 1980-2003.

International Journal of Productivity and Performance Management, v.56, n.03, p. 205-225, 2007.

JOHNSTON, R. Service operations management: return to roots. International Journal of Operations and Production Management, v.19, n.2, p.104-124, 1999.

JOHNSTON, R.; JONES, P. Service productivity towards understanding the relationship between operational and customer productivity. International Journal of Productivity and Performance Management, v.53, n.03, p. 201 -213, 2004.

JOHNSTON, R.; CLARK, G. Service operations management: improving service delivery. London: Pearson Education Limited, 2008.

JUNQUEIRA, E. R. et al. Modelo novaes para análise da produtividade e da eficiência dos operadores logísticos do Brasil: um estudo de sua aplicabilidade para os anos de 2005 e 2006. Revista Produção Online, Edição Especial, 2007. 
KITCHENHAM, B. Procedures for performing systematic reviews. Eversleigh: Keele University Technical Report, 2004.

KLASSEN, K.; RUSSELL, R.; CHRISMAN, J. Efficiency and productivity measures for high contact services. The Service Industries Journal (SIJ), v.18, n.4, p. 1-18, 1998.

KUMAR, S.; GULATI, R. Measuring efficiency, effectiveness and performance of Indian public sector banks. International Journal of Productivity and Performance Management, v.59, n.01, p. 51-74, 2009.

KUPERS, W. Phenomenology of embodied productivity in services. International Journal of Service Industry Management (IJSIM), v.9, n.4, p 337-358, 1998.

LOOY, B. V.; GEMMEL, P. et al. Dealing with productivity and quality indicators in a service environment: some field experiences. International Journal of Service Industry Management (IJSIM), v.09, n.4, p. 359-376, 1998.

LOVATO, P. A. et al. Meta-análise em pesquisas científicas: enfoque em metodologias. Revista Brasileira de Zootecnia, v.36, suplemento especial, p.285294, 2007.

LOVELOCK, C. H.;WIRTZ, J. Marketing de Serviços: pessoas, tecnologia e resultados. São Paulo: Pearson Prentice Hall, 2006.

MACHUCA, J. A.D.; GONZALEZ-ZAMORA, M. del M.; AGUILAR-ESCOBAR, V. G. Service operations management research. Journal of Operations Management, $v$. 25, p.585-603, 2007.

MAROTO, A.; RUBALCABA, L. Services productivity revisited. The Service Industries Journal (SIJ), v.28, n.3, p. 337-353, 2008.

MARTIN JR, C. R.; HORNE, D. A.; CHAN, W.S. A perspective on client productivity in business-to-business consulting services. International Journal of Service Industry Management (IJSIM), v.12, n.02, p. 137-157, 2001.

MARTINS, M. E. A dinâmica das relações na produção científica de gestão de serviços: um estudo sob a perspectiva da Análise de Redes Sociais. 2009. $113 \mathrm{f}$. Dissertação (Mestrado em Administração) - Escola de Administração de Empresas de São Paulo - Fundação Getulio Vargas, São Paulo, 2009.

MCLAUGHLIN, C. P.; COFFEY, S. Measuring productivity in services. International Journal of Service Industry Management (IJSIM), v.1, n.1, p. 46-64, 1990.

MILLWARD, R. The UK Services sector, productivity change and the recession in long-term perspective. The Service Industries Journal (SIJ), v.8, n.3, p. 263-276, 1988.

MOREIRA, D. A. Medida da produtividade na empresa moderna. São Paulo: 
Pioneira, 1991.

NACHUM, L. Measurement of productivity of professional services. International Journal of Operations and Production Management (IJOPM), v.19, n.9, p. 922949, 1999a.

NACHUM, L. The productivity of intangible factors of production: some measurement issues applied to swedish management consulting firms. Journal of Service

Research (JSR), v.02, n.02, p. 123-137, 1999b.

NAKANO, D. Métodos de pesquisa adotados na engenharia de produção e gestão de operações. In: CAUCHICK, P. A. (Org.). Metodologia de pesquisa em engenharia de produção e gestão de operações. Rio de Janeiro: Elsevier, 2010. p.63-72.

NAVARRO, J. L.; CAMACHO, J. A. Productivity of the service sector: a regional perspective. The Service Industries Journal (SIJ), v.21, n.1, p. 123-148, 2001.

NIE, W.; KELLOGG, D. L. How professors of operations management view service operations?, Production and Operations Management, v.8, n.3, p.339-355, 1999.

OJASALO, K. Conceptualizing productivity in services. Helsinki: Swedish School of Economics and Business Administration, 1999.

PARKAN, C. Benchmarking operational performance: the case of two hotels.

International Journal of Productivity and Performance Management, v.54, n.8, p. 679-696, 2005.

PARKAN, C. Measuring the operational performance of a public transit company. International Journal of Operations and Production Management (IJOPM), v.22, n.06, p. 693-720, 2002.

QUINN, J. B.; BAILY, M. N. Information technology: the key to service performance. Journal of Service Research (JSR), v.12, n.3, p. 37-41, 1994.

$\mathrm{ROACH}, \mathrm{S}$. S. Services under siege: the restructuring imperative. Harvard Business Review (HBR), September/October, p.82-91, 1991.

ROTH, A.V., MENOR, L.J. Insights into service operations management: a research agenda. Production and Operations Management, v.12, n.2, p.145-216, 2003.

SAHAY, B.S. Multi-factor productivity measurement model for service organization. International Journal of Productivity and Performance Management, v.54, n.1, p.7-22, 2005.

SELLERS-RUBIO, R.; MAS-RUIZ, F. An empirical analysis of productivity growth in retail services: evidence from Spain. International Journal of Service Industry Management (IJSIM), v.18, n.01, p. 52-69, 2007. 
SHAFTI, F.; VAN DER MEER, R.; WILLIAMS, T. An empirical approach to service classification for productivity management studies. The Service Industries Journal (SIJ), v.27, n.6, p. 709-730, 2007.

SIGALA, M.; JONES, P.; LOCKWOOD, A. Productivity in hotels: a stepwise data envelopment analysis of hotels rooms division processes. The Service Industries Journal (SIJ), v. 25, n.1, p. 61-81, 2005.

SINK, D. S.; TUTTLE, T. C. Planejamento e medição para a performance. Rio de Janeiro: Qualitymark Editora, 1993.

SILVESTRO, R.; FITZGERALD, L.; JOHNSTON, R. Towards a classification of service process. International Journal of Service Industry Management, v.3, n.3, p.62-75, 1992.

SCHMENNER, R. W. Administração de operações em serviços. São Paulo: Futura, 1999.

SOUSA, M. da C. S. de; RAMOS, F. S. Eficiência técnica e retornos de escala na produção de serviços públicos municipais: o caso do nordeste e do sudeste brasileiros. RBE, v.53, n.4, p. 433-461, 1999.

TORRES JÚNIOR, N.; MIYAKE, D.I. Melhoria de desempenho em serviços: alternativas para lidar com o trade-off entre eficiência e eficácia. Revista Produção Online, v.11, n.1, p. 162-193, 2011.

TRANFIELD, D.; DENYER, D.; SMART, P. Towards a Methodology for Developing Evidence-Informed Management Knowledge by Means of Systematic Review. British Journal of Management, v.14, p.207-222, 2003.

VUORINEN, I.; JARVINEN, R.; LEHTINEN, U. Content and measurement of productivity in the service sector: conceptual analysis with an illustrative case from the insurance business. International Journal of Service Industry Management (IJSIM), v.9, n.4, p. 377-396, 1998.

WAAL, A. A. de; COEVERT, V. The effect of performance management on the organizational results of a bank. International Journal of Productivity and Performance Management, v.56, n.5/6, p. 397-416, 2007.

WEMMERLOV, U. A taxonomy for service process and its implications for system design. International Journal of Service Industry Management, n. 1\&3, p. 20-40, 1990.

WOODBURY, K.; DOLLERY, B. Efficiency measurement in australian local government: the case of new south wales municipal water services. Journal of Service Research (JSR), v.21, n.5, p. 615-636 , 2004.

WOODMAN, J.; CLARK, J.; RIMMINGTON, M. Productivity in Hospital Kitchens. The Service Industries Journal (SIJ), v.16, n.3, p. 368-378, 1996. 
ZEITHAML, V. A.; BITNER, M. J. Marketing de serviços: a empresa com foco no cliente. 5.ed. Porto Alegre: Bookman, 2011.

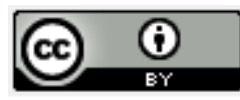

Artigo recebido em 23/11/2011 e aceito para publicação em 16/12/2012. 
ANEXO I - Tabelas de Codificação

Tabela 10 - Codificação da classificação dos artigos selecionados sobre Produtividade em Serviços

\begin{tabular}{|c|c|}
\hline \multicolumn{2}{|r|}{ C1 - Tipo de Estudo } \\
\hline TC & Teórico Conceitual \\
\hline MS & Modelagem /Simulação \\
\hline EC & Estudo em Campo: Estudo de Caso, Pesquisa-Ação, Etnografia, etc. \\
\hline SY & Survey \\
\hline OS & Outros: Experimento, Dados Históricos, Base de Dados \\
\hline \multicolumn{2}{|r|}{ C2 - Setor Pesquisado } \\
\hline A & Comercio e distribuição \\
\hline B & Correios e serviços de courier \\
\hline C & Instituições financeiras e de seguros \\
\hline $\mathrm{D}$ & Saúde \\
\hline E & Serviços profissionais \\
\hline $\mathrm{F}$ & Serviços públicos e empresas sem fins lucrativos \\
\hline G & Telecomunicações \\
\hline $\mathrm{H}$ & Transporte \\
\hline I & Turismo, entretenimento, lazer e cultura \\
\hline $\mathrm{J}$ & Outros \\
\hline \multicolumn{2}{|r|}{ C3 - Filiação dos Autores } \\
\hline IE & Instituições de Ensino e Pesquisa \\
\hline EP & Empresas \\
\hline \multicolumn{2}{|r|}{ C4 - Abordagem Metodológica Predominante } \\
\hline QL & Qualitativa \\
\hline QT & Quantitativa \\
\hline LT & Quantitativa e Qualitativa \\
\hline
\end{tabular}

Tabela 11 - Temas abordados pelos trabalhos

\begin{tabular}{|ll|}
\hline & \multicolumn{1}{c|}{ C5 - Temas Abordados } \\
\hline A1 & Análises comparativas de desempenho em termos de produtividade \\
A3 & Contextualização da produtividade em serviços \\
A4 & Estratégias e métodos para a melhoria da produtividade \\
\hline & Proposição de indicadores de produtividade \\
\hline M1 & C6 - Métodos utilizados nas análises comparativas \\
M2 & Análise de Regressão \\
M3 & Outro \\
\hline
\end{tabular}




\section{ANEXO II}

C1 : Tipo de Estudo; C2 : Setor Pesquisado; C3 : Filiação dos Autores; C4 : Abordagem Metodológica Predominante (C1 a C4 Tabela 1 do anexo I); C5 : Temas Abordados; C6 : Métodos utilizados nas análises comparativas (C5 e C6 Tabela 2 do anexo I)

\begin{tabular}{|c|c|c|c|c|c|c|}
\hline ARTIGOS & $\mathrm{C} 1$ & $\mathrm{C} 2$ & C3 & $\mathrm{C} 4$ & C5 & C6 \\
\hline Al-Shammari, M.(1999) & MS & $\mathrm{D}$ & IE & QT & A1 & M1 \\
\hline Armistead, C.; Machin, S. (1998) & EC & $\mathrm{B}$ & IE/EP & LT & A2/A4 & \\
\hline Biema, M.Van; Greenwald, B. (1997) & $\mathrm{TC}$ & & IE & & $\mathrm{A} 2$ & \\
\hline Blois, K. J.(1984) & $\mathrm{TC}$ & & - & & A2 & \\
\hline $\begin{array}{l}\text { Borenstein, D.; Becker, J.L.; Prado, } \\
\text { V. J. do; (2004) }\end{array}$ & MS & B & IE/EP & QT & $\mathrm{A} 1$ & M1 \\
\hline Chen, T.; Chen, C.; Peng, S. (2008) & MS & $\mathrm{C}$ & IE & QT & A1 & M1 \\
\hline D'Alcantara, G. (1987) & TC & & - & & $\mathrm{A} 2$ & \\
\hline Delaunay, J. (1999) & SY & $\mathrm{F}$ & IE & QT & A3 & \\
\hline Drucker, P.(1991) & $\mathrm{TC}$ & & $\mathrm{IE}$ & & A2 & \\
\hline Fletcher, J.; Snee, H. (1985) & $\mathrm{TC}$ & & - & & $\mathrm{A} 2$ & \\
\hline Georges, I.(2002) & EC & G & IE & $\mathrm{QL}$ & $\mathrm{A} 2$ & \\
\hline Haywood-Farmer, J.; Nollet, J.(1985) & $\mathrm{TC}$ & $E$ & IE & & A3 & \\
\hline
\end{tabular}




\begin{tabular}{|c|c|c|c|c|c|c|}
\hline ARTIGOS & C1 & $\mathrm{C} 2$ & C3 & $\mathrm{C} 4$ & C5 & C6 \\
\hline Henrici, S.B.(1981) & $\mathrm{TC}$ & & EP & & A2/A4 & \\
\hline Hilmola, O. (2007) & MS & $\mathrm{H}$ & IE & QT & A1 & M1 \\
\hline Johnston, R.; Jones, P. (2004) & TC & & IE & & A2/A4 & \\
\hline Junqueira, E. R. et al. (2007) & MS & $\mathrm{H}$ & IE & QT & A1 & M2 \\
\hline $\begin{array}{l}\text { Klassen, K.; Russell, R.; Chrisman, } \\
\text { J. (1998) }\end{array}$ & $\mathrm{TC}$ & $\begin{array}{l}\mathrm{J}=\text { Serviços de } \\
\text { alto contato }\end{array}$ & IE & & A2/A4 & \\
\hline Kumar, S.; Gulati, R. (2009) & MS & $\mathrm{C}$ & IE & QT & A1 & M1 \\
\hline Kupers, W. (1998) & $\mathrm{TC}$ & & IE & & $\mathrm{A} 2$ & \\
\hline $\begin{array}{l}\text { Looy, B. Van; Gemmel, P.; et al.; } \\
\text { (1998) }\end{array}$ & $\mathrm{EC}$ & $\mathrm{D}$ & IE/EP & $\mathrm{LT}$ & A4 & \\
\hline Maroto, A.; Rubalcaba, L.(2008) & OS & $\begin{array}{l}\mathrm{J} \text { - Vários } \\
\text { setores }\end{array}$ & IE & QT & $\mathrm{A} 2$ & \\
\hline $\begin{array}{l}\text { Martin Jr, C. R.; Horne, D. A.; Chan, } \\
\text { W. S. (2001) }\end{array}$ & OS & $E$ & IE/EP & - & A2/A3 & \\
\hline McLaughlin, C. P.; Coffey, S. (1990) & TC & & IE & & A2/A4 & \\
\hline Millward, R. (1988) & OS & $\begin{array}{l}\text { J - Vários } \\
\text { setores }\end{array}$ & IE & QT & A1/A2 & M3 \\
\hline Nachum, L. (1999b) & MS & $E$ & IE & QT & A1/A2 & $\mathrm{M} 1 / \mathrm{M} 2$ \\
\hline Nachum, L. (1999a) & MS & $E$ & IE & QT & A1/A2 & M1 \\
\hline Navarro, J.L.; Camacho, J. A. (2001) & MS & $\begin{array}{l}\text { J - Vários } \\
\text { setores }\end{array}$ & IE & QT & A1 & M1/M3 \\
\hline Parkan, C.(2002) & MS & $\mathrm{H}$ & IE & QT & A1/A4 & M3 \\
\hline Parkan, C.(2005) & MS & I & IE & QT & A1/A4 & M3 \\
\hline Quinn, J. B.; Baily, M. N. (1994) & OS & $\mathrm{J}-$ Vários & IE & & A2 & \\
\hline
\end{tabular}




\begin{tabular}{|c|c|c|c|c|c|c|}
\hline & & setores & & & & \\
\hline ARTIGOS & C1 & $\mathrm{C} 2$ & C3 & $\mathrm{C} 4$ & C5 & $\mathrm{C} 6$ \\
\hline Roach, S. S. (1991) & OS & $\begin{array}{l}\text { J - Vários } \\
\text { setores }\end{array}$ & EP & & $\mathrm{A} 2$ & \\
\hline \multicolumn{7}{|l|}{$\begin{array}{l}\text { Sellers-Rubio, R.; Mas-Ruiz, F. } \\
\text { (2007) }\end{array}$} \\
\hline Sahay (2005) & SY & $\begin{array}{l}\mathrm{J} \text { - Vários } \\
\text { setores }\end{array}$ & $\mathrm{IE}$ & & A2/A3 & \\
\hline $\begin{array}{l}\text { Sigala, M.; Jones, P.; Lockwood, A. } \\
\text { (2005) }\end{array}$ & MS & I & $\mathrm{IE}$ & QT & A1 & M1 \\
\hline $\begin{array}{l}\text { Sousa, M. da C. S. de; Ramos, F. S. } \\
\text { (1999) }\end{array}$ & MS & $\mathrm{F}$ & $\mathrm{IE}$ & QT & A1 & M1 \\
\hline $\begin{array}{l}\text { Torres Júnior, N. ; Miyake, D.I.; } \\
\text { (2011) }\end{array}$ & EC & $\mathrm{I}, \mathrm{J}$ & IE & QL & A3 & \\
\hline $\begin{array}{l}\text { Vuorinen, I.; Jarvinen, R.; Lehtinen, } \\
\text { U. (1998) }\end{array}$ & $\mathrm{EC}$ & $\mathrm{C}$ & $\mathrm{IE}$ & QL & A2/A4 & \\
\hline Waal, A. A. De; Coevert, V. (2007) & EC & C & IE & LT & A1 & M3 \\
\hline Woodbury, K.; Dollery, B. (2004) & MS & $\mathrm{F}$ & IE & QT & A1 & M1 \\
\hline $\begin{array}{l}\text { Woodman, J.; Clark, J.; Rimmington, } \\
\text { M. (1996) }\end{array}$ & SY & D & - & QT & A1 & M3 \\
\hline
\end{tabular}

